\title{
Article
}

\section{A Taxonomy of Technologies for Human-Centred Logistics 4.0}

\author{
Alexandra Lagorio*(D), Chiara Cimini (D), Fabiana Pirola and Roberto Pinto (D) \\ Department of Management, Information and Production Engineering, University of Bergamo, \\ 24044 Dalmine, Italy; chiara.cimini@unibg.it (C.C.); fabiana.pirola@unibg.it (F.P.); roberto.pinto@unibg.it (R.P.) \\ * Correspondence: alexandra.lagorio@unibg.it
}

\section{check for}

updates

Citation: Lagorio, A.; Cimini, C.; Pirola, F.; Pinto, R. A Taxonomy of Technologies for Human-Centred Logistics 4.0. Appl. Sci. 2021, 11, 9661. https://doi.org/10.3390/app11209661

Academic Editor: Francesco Facchini

Received: 9 September 2021

Accepted: 14 October 2021

Published: 16 October 2021

Publisher's Note: MDPI stays neutral with regard to jurisdictional claims in published maps and institutional affiliations.

Copyright: (c) 2021 by the authors. Licensee MDPI, Basel, Switzerland. This article is an open access article distributed under the terms and conditions of the Creative Commons Attribution (CC BY) license (https:/ / creativecommons.org/licenses/by/ $4.0 /)$.

\begin{abstract}
Following the spread of the Industry 4.0 paradigm, the role of digital technologies in manufacturing, especially in production and industrial logistics processes, has become increasingly pivotal. Although the push towards digitalization and processes interconnection can bring substantial benefits, it may also increase the complexity of processes in terms of integration and management. To fully exploit the potential of technology, companies are required to develop an in-depth knowledge of each operational activity and related human aspects in the contexts where technology solutions can be implemented. Indeed, analyzing the impacts of technology on human work is key to promoting human-centred smart manufacturing and logistics processes. Therefore, this paper aims at increasing and systematizing knowledge about technologies supporting internal logistics working activities The main contribution of this paper is a taxonomy of the technologies that may be implemented in the different internal logistics areas to support a Logistics 4.0 model. Such a contribution is elaborated in accordance with a deductive approach (i.e., reasoning from the particular to the general), and backed up by an analysis of the literature. The taxonomy represents a useful framework to understand the current and possible technological implementations to drive logistics processes towards Logistics 4.0, with specific attention to the relation between human operators and technologies.
\end{abstract}

Keywords: taxonomy; logistics process; industry 4.0 technologies; human-centered

\section{Introduction}

In recent years, in the aftermath of the substantial spread of Industry 4.0 and digitalization paradigms, digital technologies have played an increasingly important role in industrial production and logistics [1]. Connected machines, automated warehouses, Internet of Things (IoT) applications, autonomous vehicles, and drones, to name a few, can bring considerable benefits, especially in terms of waste and risks reduction, as well as productivity and safety increase in the working environment. However, the introduction of digital technologies in a production or logistics process always causes an increase in the complexity of overall system management [2]. A growth in complexity often affects negatively the workforce, who may have to adapt to a working environment that requires new skills, as well as the company, which may have to deal with new operational models, additional investments (e.g., cybersecurity), and with the need to apply standards not only in its departments but often also with suppliers and customers [3].

For these reasons, many companies are still in a transition phase from traditional production and logistics methods and management practices to more innovative ones [4]. There are still knowledge gaps regarding the technologies to be implemented in production and logistics processes, that can translate into resistance to technological innovation and fears of managing increased costs, impacts, complexity, and changes. Therefore, it becomes essential to bridge these knowledge gaps helping companies understand which technologies are the most appropriate to be implemented considering the company goals and the investments that can be afforded [5].

In particular, the logistics area has been affected by a rapid acceleration towards the necessity of technologies implementation. This acceleration can be attributed to the fact 
that the market increasingly requires higher service levels and shorter lead and fulfillment times for the supply of mass customized productions [6]. Moreover, the phenomenon of digitalization is pushing for better communication and data sharing between suppliers and customers to increase supply chains flexibility and resilience, which are increasingly necessary as the supply crisis of some essential products (such as personal protective equipment) during the pandemic period have shown [7]. In order to meet these market requirements, changes are occurring both in internal logistics and in the whole supply chain: correspondingly, the concept of Logistics 4.0 has emerged to represent "the logistical system that enables the sustainable satisfaction of individualized customer demands without an increase in costs, and supports this development in industry and trade using digital technologies" [8], describing specific applications of Industry 4.0 in the area of logistics [9]. However, the transition from traditional logistics to Logistics 4.0, namely introducing technologies and new operational models in the management of logistics systems, will bring benefits but also possible adverse effects (e.g., increased complexity) for which it is necessary to be aware and prepared. Furthermore, the role of humans in the Logistics 4.0 will be crucial to properly exploit the potential of technologies [8].

Therefore, this paper aims at increasing and systematizing knowledge about Industry 4.0 technologies supporting industrial logistics working activities. In particular, in this paper we present a taxonomy-developed using a deductive approach and an extensive literature review - to classify the main Industry 4.0 technologies implemented in industrial logistics according to three main categories: internal logistics activities, flow types, and human-technology relations. The taxonomy, classifying or categorizing a body of knowledge, helps in sharing and communicating relevant information about the subject being studied, thereby representing a useful framework to understand and explore the current and possible technological implementations to drive logistics processes towards Logistics 4.0, with specific attention to the relation between human operators and technologies.

This paper is organized as follows. First, the research methodology is presented, including the taxonomy construction rules (Section 2). Then, the definition of the main taxonomy categories and objects will be presented (Section 3). After that, the results obtained will be described and discussed (Section 4). An analysis of the leading research evidence, limitations, and future research developments concludes the paper (Section 5).

\section{Methodology}

The research methodology adopted to devise a proper taxonomy of technologies to guide practitioners in choosing the most suitable technological applications in industrial contexts is composed of several steps, that will be described in the following.

According to the Oxford Dictionary, a taxonomy represents "the scientific process of classifying things" or "a particular system of classifying things". Since the main objective of taxonomies is to classify something, they represent a qualitative research design method, able to adapt to novel and scantly explored topics since they bring order in complex domains, and can be used for ex post theory building [10]. In particular, concerning technologies, taxonomies offer definitions and distinctions, and help define specifications for implementation [11]. Although taxonomies are often developed ad hoc for specific topics, it is also possible to find in literature structured approaches to build them, including both inductive and deductive approaches $[10,12]$. Generally, developing a taxonomy is a multistep process that involves identifying a classification scheme, and evaluating the population according to the proposed scheme [13]. To meet the purpose of identify a classification scheme, designing a taxonomy includes (i) defining the units of classifications (i.e., categories); (ii) describing the different attributes (i.e., dimensions) of each category; (iii) assigning the subject instances (i.e., objects) to the defined categories and dimensions.

Following this scheme, in this paper, we develop a taxonomy based on a deductive approach; in Figure 1, the research workflow is presented, adapted from the conceptual-toempirical process proposed in $[10,14]$. 


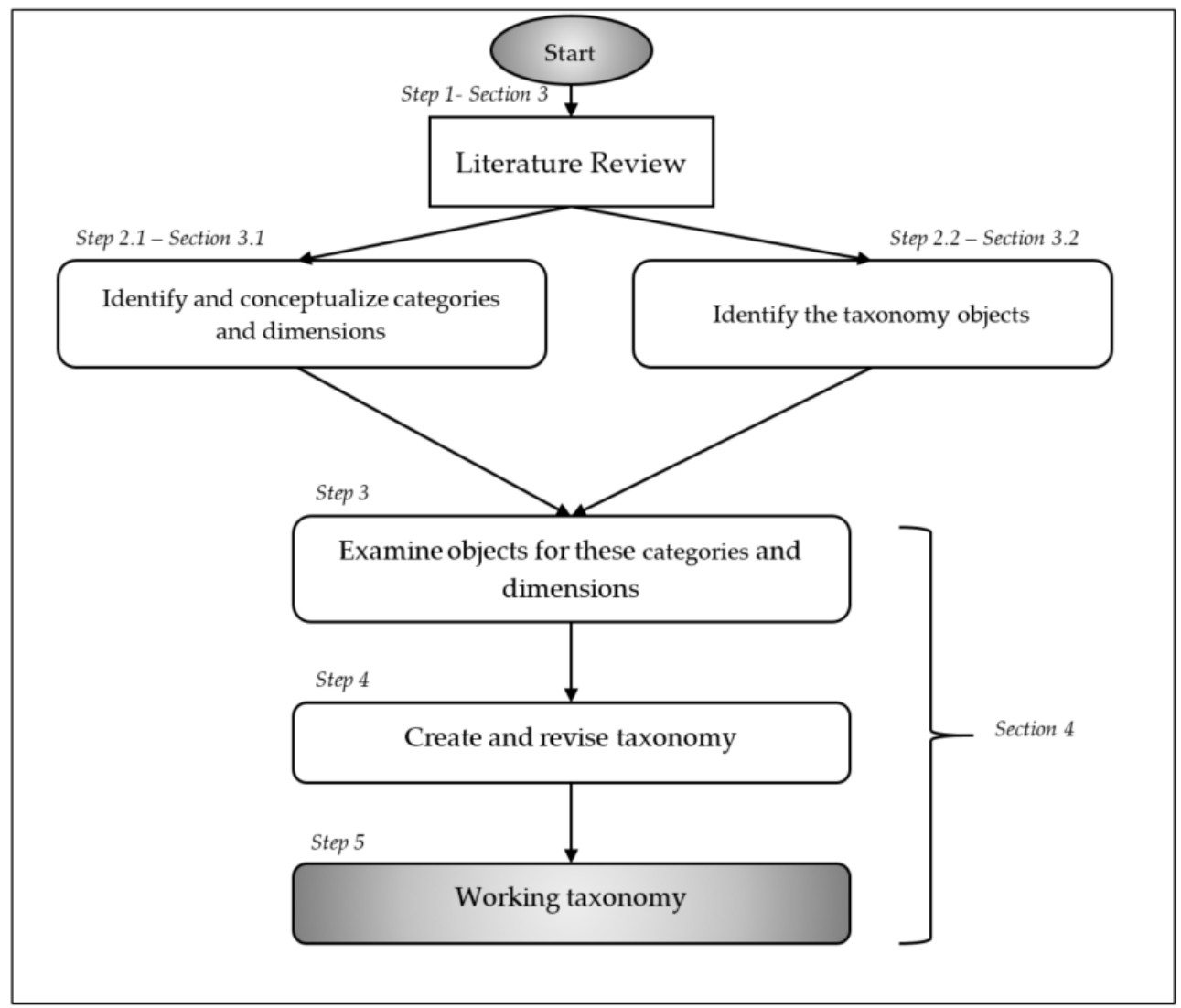

Figure 1. Research workflow.

The research starts from the definition of the three categories for the taxonomy; onethe internal logistics activities - has been derived directly from literature, while the other two- the flow types and the human-technology relation-have been conceptualized ex novo by the authors, based on both scientific literature and on the authors previous experience concerning these topics. At this point, a review of the extant literature concerning internal logistics activities, flow types and the human-technology relation has been performed (Step 1). Relevant literature has been retrieved from well-established databases such as Scopus, Web of Science, Google Scholar, and ScienceDirect to be inclusive concerning the publications types (e.g., journal papers, conference proceedings). This literature analysis, presented in Section 3.1, has two objectives: first, to identify and conceptualize the categories that will be used for the classification, specifying the different dimensions for each of them (Step 2.1); second, to identify the population of taxonomy objects to be classified (Step 2.2). The categories are generally chosen following the purpose of the study, and this choice is recognized as a crucial step in taxonomy development [10]. A deductive line of reasoning has been followed in this study to understand the domain of interest and propose the categories [15]. For each category, then, the dimensions of classification have been defined (Figure 2). The explanation of all the categories and their dimensions is presented in Section 3.1.

The following research step (Step 3) has been the examination of all the objects of the population (i.e., the technologies) according to the defined categories. In doing this, each technology has been analyzed according to the definitions and the application examples found in the literature (see also Table 5 in Section 3.2). 


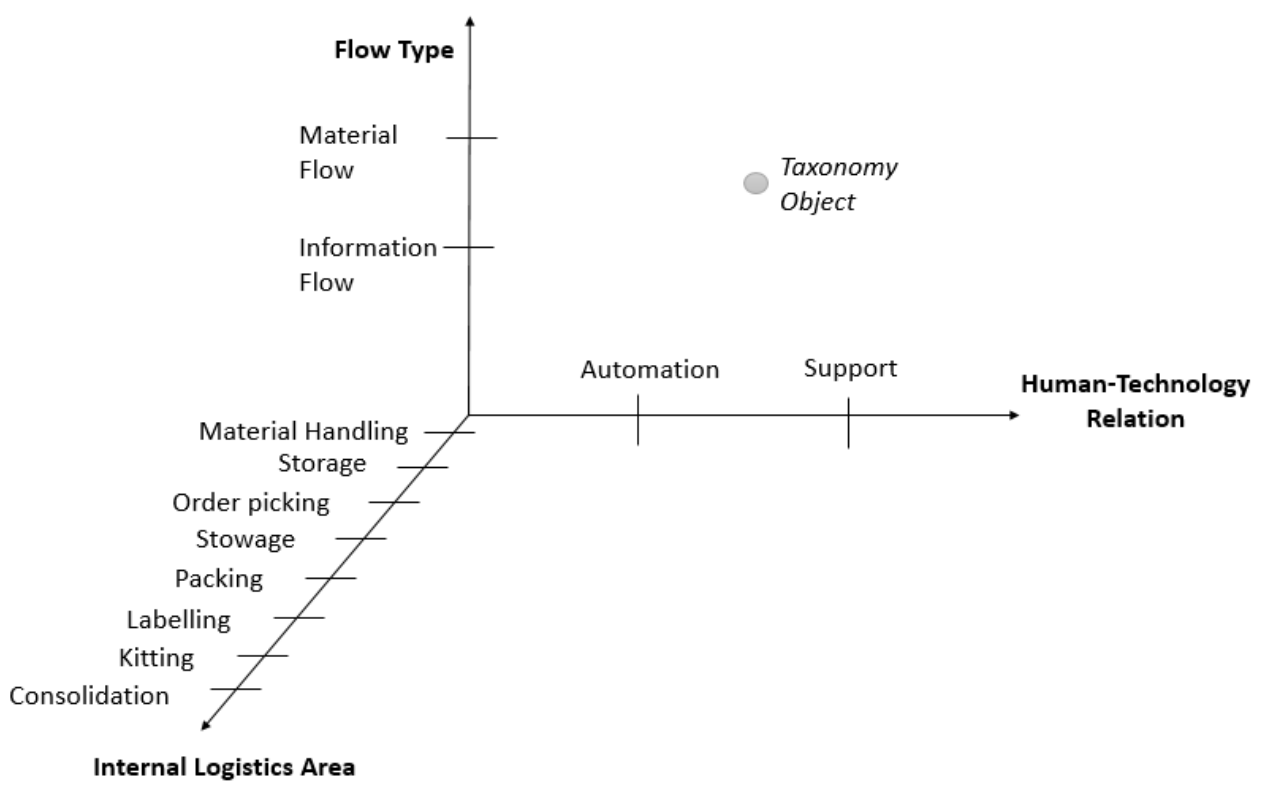

Figure 2. Taxonomy categories and dimensions.

At this point, the first draft of the taxonomy has been created (Step 4). After this first attempt in the classification of technologies, it appeared clearly that a minor revision of the category related to the logistics area was required. In particular, some areas have been merged into a unique dimension since there was complete overlap between them as stated in the introduction of Section 4. This revision phase led to the final taxonomy (Step 5). In addition, the evaluation and classification of technologies into the defined dimensions in order to build the taxonomy has also been guided by the expertise of the researchers, which has been acquired during multiple experiences and case studies research in collaboration with industrial companies. The resulting outcome of this research is presented in Section 4.1 and discussed in Section 4.2.

\section{The Taxonomy Categories, Dimensions and Objects}

In this section, the scientific literature concerning the three categories, the dimensions and the objects of the taxonomy is reported, in order to describe their different dimensions.

\subsection{Taxonomy Categories and Dimensions Identification}

\subsubsection{Internal Logistics Activities}

Internal logistics can be defined as "planning, execution, and control of the company's physical flow and internal information, seeking to optimize the resources, processes, and services with the highest possible profit" [16]. From this definition, it is easy to understand the complexity of internal logistics, which is made up of many sub-activities and must necessarily integrate and interact with other departments in the company (e.g., production and purchasing), and use information from the supply chain (e.g., suppliers and customers). Because of this complexity, however, logistics can play a unique role as a boundary-spanning interface between marketing and production, becoming a potential source of competitive advantage [17]. The importance of the logistics role combining with the high costs of logistics explains why internal logistics is one of the critical areas for implementing new technologies. However, if the various activities that make up internal logistics have to be identified, a defining boundary must be set. The boundaries of internal logistics correspond to the physical boundaries of the company. Consequently, for the purposes of this research, we consider as internal logistics operations all the activities related to the movement and storage of raw materials, semi-finished and finished products within the company's boundaries [18]. These main activities of internal logistics that 
constitute the dimensions of the first category of the taxonomy and their definition are shown in Table 1.

Table 1. Internal logistics activities.

\begin{tabular}{|c|c|c|}
\hline Internal Logistics Activities & Definition & References \\
\hline Material Handling & $\begin{array}{l}\text { Material handling is the movement of raw materials and products } \\
\text { inside a factory throughout manufacturing, warehousing, distribution, } \\
\text { consumption, and disposal. }\end{array}$ & [19] \\
\hline Storage & $\begin{array}{l}\text { Storage is the activity of storing products at warehouses and logistics centers. } \\
\text { Its role is to provide a steady supply of goods to the production line or to the } \\
\text { market to fill the temporal gap between two different production lines or } \\
\text { between producers and consumers. }\end{array}$ & {$[20]$} \\
\hline Order picking & $\begin{array}{l}\text { The order picking or order preparation operation is one of a logistic } \\
\text { warehouse's processes. It consists of taking and collecting articles in a specified } \\
\text { quantity before shipment to satisfy internal production or customers' orders. }\end{array}$ & {$[21]$} \\
\hline Stowage & $\begin{array}{l}\text { The stowage decision determines how arriving products are distributed in a } \\
\text { storage system or warehouse. This activity is particucular important for large } \\
\text { warehouses that are organized into distinct storage zones. }\end{array}$ & [22] \\
\hline Packing & $\begin{array}{l}\text { Packing is a coordinated activity of preparing goods for safe, secure, } \\
\text { efficient, and practical handling, transport, distribution, and storage. Packing } \\
\text { activities also have to facilitate distribution, protect both products and the } \\
\text { environment and provide information about products conditions } \\
\text { and production information. }\end{array}$ & [23] \\
\hline Labelling & $\begin{array}{l}\text { Labelling is the activity related to the product identification. It is a printed } \\
\text { information that is bonded to the product for recognition and provides } \\
\text { detailed information about it (e.g., content, origin, usage modes). }\end{array}$ & {$[24]$} \\
\hline Kitting & $\begin{array}{l}\text { Kitting is the activity of compiling multiple components / products } \\
\text { into a single "kit" for bring the materials to be processed on the production } \\
\text { line or for directly shipping finish products to the customer. }\end{array}$ & [25] \\
\hline Consolidation & $\begin{array}{l}\text { Consolidation is the process where a company combines } \\
\text { several smaller shipments into one full delivery. }\end{array}$ & [26] \\
\hline
\end{tabular}

\subsubsection{Flow Types}

There are mainly three flows that intercede between suppliers and customers in logistics: flows of materials, information, and money [27]. Leaving aside the flows of money that usually go up the chains from the customers to the suppliers and are out of the scope of our analysis, the other two types of flow can go in both directions. Flows of materials and products usually go from the suppliers to the customers, but can include also inverse flows of returned products or products to dispose. In the same way, information flows can go both from supplier to customer and vice versa. The information flows from supplier to customer allow, in fact, correct management of the supplies (as an example, communicating in advance the eventual delays in supplying the raw materials is crucial for the production scheduling). In contrast, the information flows from the customers to the suppliers allow a better forecast of the demand and a better production planning (as an example, avoiding the so-called bullwhip effect).

Moreover, in the last years, the concept of digital supply chains (DSC) has been emerging as the next generation of designing, producing, and supplying goods, relying on interconnected systems, automatization of plants, and collaborative digital platforms [28]. In particular, the literature showed that the use of technologies is positively correlated to the joint performance of the suppliers and the focal company, and digitalization allows companies' openness to share core information with their suppliers and vice versa [29].

Horizontal integration is one of the Industry 4.0 pillars since it supports dynamic and flexible supply chains, which allows more intelligent and optimized internal logistics processes [28,30]. 
In this context, the efficiency of the Logistics 4.0 activities not only depends on the material flows and how they are managed, but also on data and information flows since they are essential to support operational and tactical decision-making for internal logistics management enabling horizontal integration. Consequently, information flows and material flows are the two dimensions included in the flow type category of the taxonomy and their definitions are reported in Table 2.

Table 2. Flow types.

\begin{tabular}{ccc}
\hline Flow Types & Definition & References \\
\hline Material flows & $\begin{array}{c}\text { The material flows are all the flows of raw materials, work-in-progress components and } \\
\text { finshed products going from the suppliers to the customers. }\end{array}$ \\
\hline Information flows & $\begin{array}{c}\text { The information flows are all data and information flows related to the production and } \\
\text { the logistics processes useful for a better forecast of the demand and a better production } \\
\text { planning. These flows go from the customers to the suppliers and vice versa. }\end{array}$ \\
\hline
\end{tabular}

\subsubsection{Human-Technology Relation}

Logistics 4.0 is considered as the evolution of traditional logistics towards the Industry 4.0 paradigm. The main scientific literature on this topic suggests that, while the main logistics activities do not undergo variations, the introduction of 4.0 technologies has an important impacts on the human factors related to the logistics operators' tasks [8]. If we consider automation technologies or intelligent digital applications, logistics operators could be entirely replaced in some cases, especially in all those repetitive, risky, and heavy activities. Nevertheless, despite the supposed extensive use of technology, as suggested by the maturity models defined by [32] for Logistics 4.0 , the human role will be crucial in supervision and controlling activities. For instance, the human-technology interactions will be determinant to improve decision-making.

For these reasons, if we consider the category of the human-technology relation, it is possible to identify two dimensions: (i) automation; ii) support (Table 3). Automation represents the situation in which operators are completely replaced by a machine/robot or an automatic computerized systems (such as AGVs) that are in charge of the tasks that were previously performed by a human worker. This case is more related to operators and individual tasks that are strongly requiring the use of physical force (e.g., material handling) and continuous/repetitive activities (e.g., manual packaging, picking operations) or that do not bring added value to the process, such as inventory control and scrap disposal [33]. Support dimension, conversely, refers to all the situations in which human and technology coexist in the performance of working tasks. Also in this case, there are several ways in which human and technology can interact. The support can consist in collaborative work (e.g., an operator working with a cobot) or the human worker can be augmented or assisted by technology. Augmentation is more referred to the technologies that are able to enhance human capabilities (e.g., exoskeleton), while assistance refers to the applications that provides workers with additional information and instructions (e.g., softbots).

Table 3. Human-technology relation.

\begin{tabular}{ccc}
$\begin{array}{c}\text { Human-Technology } \\
\text { Relation }\end{array}$ & Definition & References \\
\hline Automation & $\begin{array}{c}\text { Automation represents the situation in which operators are completely replaced by a } \\
\text { machine/robot or an automatic computerized system that become in charge of the } \\
\text { tasks that were previously performed by a human worker. }\end{array}$ \\
\hline Support & $\begin{array}{c}\text { Support dimension refers to all the situations in which human and technology coexist } \\
\text { in performing working tasks. }\end{array}$ \\
\hline
\end{tabular}


Finally, Table 4 summarize all the categories and the dimensions that have been identified during the second step of the research workflow and that will constitute the base of the taxonomy.

Table 4. Taxonomy categories and dimensions.

\begin{tabular}{cc}
\hline Categories & Dimensions \\
\hline & Material Handling \\
& Storage \\
Internal Logistics Activities & Order picking \\
& Stowage \\
& Packing \\
& Labelling \\
& Kitting \\
Flow Types & Consolidation \\
\hline \multirow{2}{*}{ Human-Technology Relation } & Material \\
& Information \\
\hline
\end{tabular}

\subsection{Taxonomy Objects Identification}

As stated in Section 2, technologies have been chosen as the taxonomy objects. In the introduction and the previous section, technologies have always been referred to in a generic way. In reality, different types of technologies vary according to their domain (i.e., handling, management, traceability) and main features. Moreover, it is necessary to specify that some of the technologies analyzed in this section were born and developed in the logistics field, for example, to allow the traceability of products and processes (e.g., barcode, RFID) or to perform material handling (e.g., self-driving vehicles, automated warehouses). Other technologies, instead, were born and developed in a pure production field and were then applied to the field of internal logistics (e.g., collaborative or autonomous robots or software for the management of information flows). The classification reported below is mainly based on two literature reviews on technologies in logistics [8,35]. Table 5 shows the main technological domains applied in the logistics field with a brief description of their features and functionalities. Moreover, Table 5 reports the detailed technologies/applications that emerged from literature chosen as taxonomy objects and analyzed in Section 4.1 in accordance with what was explained in Section 2 regarding the research methodology adopted.

Table 5. Main technologies implemented in a logistics context.

\begin{tabular}{|c|c|c|c|}
\hline $\begin{array}{l}\text { Technological } \\
\text { Domains }\end{array}$ & Description & Taxonomy Objects & References \\
\hline Traceability & $\begin{array}{l}\text { Barcodes are codes consisting of a group of printed bars, spaces } \\
\text { and numbers designed to be scanned and read into computer } \\
\text { memory and that contains information (such as identification) } \\
\text { about the object on which they are attached. The Radio-Frequency } \\
\text { IDentification (RFID) sensors are key technologies viewed as a } \\
\text { prerequisite or essential element in the IoT. THEY are based on } \\
\text { unique codes or tags that are read by electromagnetic devices. } \\
\text { The peculiarities of RFID are the non-necessity of a line of sight } \\
\text { between the reader and the tag, the simultaneous high-speed } \\
\text { reading of multiple tags. Beacon sensors are small, always-on } \\
\text { transmitters, which use Bluetooth Low Energy (BLE) technology } \\
\text { to broadcast signals containing several information to nearby } \\
\text { portable devices (tablets and smartphones). }\end{array}$ & $\begin{array}{l}\text { Scanners (barcodes, } \\
\text { RFID tags) } \\
\text { Auto-ID Technologies } \\
\text { (RFID) } \\
\text { Smart Sensors (beacon } \\
\text { tags) }\end{array}$ & {$[36,37]$} \\
\hline
\end{tabular}


Table 5. Cont.

\begin{tabular}{|c|c|c|c|}
\hline $\begin{array}{l}\text { Technological } \\
\text { Domains }\end{array}$ & Description & Taxonomy Objects & References \\
\hline IT/ICT/CC & $\begin{array}{l}\text { Information Technology (IT) or Information and } \\
\text { communications technology (ICT) in logistics is identified as all } \\
\text { applications used to plan, implement and control procedures to } \\
\text { transport and store goods and services from origin to } \\
\text { destination. Cloud Computing (CC) figuratively refers to a } \\
\text { bundle of virtualized and distributed resources shaped in a } \\
\text { diffuse, all-pervasive way, similar to a cloud. This type of } \\
\text { technology allows access to software applications and data } \\
\text { storage without a significant investment in infrastructure but } \\
\text { investment in software functionality and services. }\end{array}$ & $\begin{array}{c}\text { Warehouse Management } \\
\text { Systems (WMS) } \\
\text { Inventory Resources } \\
\text { Planning (IRP) } \\
\text { Order Management } \\
\text { Systems (OMS) } \\
\text { Inventory Management } \\
\text { Systems (IMS) } \\
\text { Picking Route } \\
\text { Management Systems } \\
\text { (PRMS) } \\
\text { Scheduling Management } \\
\text { Systems (SMS) }\end{array}$ & [38-40] \\
\hline Wearable devices & $\begin{array}{l}\text { Wearable devices help operators take on physical jobs that } \\
\text { would otherwise be too difficult, constantly monitoring } \\
\text { management software. }\end{array}$ & $\begin{array}{c}\text { Handheld Computers } \\
\text { (picking orders } \\
\text { information) } \\
\text { Voice-Direct Headsets } \\
\text { (voice picking) } \\
\text { Smart Glasses (pick-put to } \\
\text { light) } \\
\text { Activity Trackers (steps, } \\
\text { heart-rate) } \\
\text { Exoskeletons (lifting and } \\
\text { moving) } \\
\text { Wearable Scanners }\end{array}$ & [41-43] \\
\hline AVS/RS & $\begin{array}{l}\text { Automated vehicle storage and retrieval systems (AVS/RSs) are } \\
\text { used to achieve greater operational efficiency and competitive } \\
\text { advantage, especially in operating environments with a high } \\
\text { altitude. Autonomous vehicles provide horizontal movement } \\
\text { ( } x \text {-axis and } y \text {-axis) within a tier using rails or laser guides, while } \\
\text { lifts provide vertical movement (z-axis) between tiers. }\end{array}$ & $\begin{array}{l}\text { AGVs (picking and } \\
\text { moving) } \\
\text { Smart Fast Rotation } \\
\text { Storage Systems } \\
\text { Smart Trasloelevators } \\
\text { Smart Mini-Loaders } \\
\text { Smart Lifts and Forklifts }\end{array}$ & [44] \\
\hline Drones & $\begin{array}{l}\text { Drones could collect data from shelves doing autonomous } \\
\text { inventory control and handle small and light parcels. }\end{array}$ & $\begin{array}{l}\text { Drones (inventory, picking } \\
\text { and moving) } \\
\text { Collaborative Robots } \\
\text { (picking) }\end{array}$ & [45] \\
\hline Logistics Robots & $\begin{array}{l}\text { Logistics robots are robots with one or more grippers to pick up } \\
\text { and move items within a logistics operation such as } \\
\text { warehouses, sorting centers, or last-mile fulfillment centers. }\end{array}$ & $\begin{array}{l}\text { Collaborative Robots } \\
\text { (load-n'-unload, } \\
\text { inspection, kitting, and } \\
\text { packing) } \\
\text { Industrial Robots } \\
\text { (inspection, kitting and } \\
\text { packing) } \\
\text { Labelling Systems }\end{array}$ & [46] \\
\hline
\end{tabular}

\section{Taxonomy of Technology}

This paper aims to provide a taxonomy of technologies for Logistics 4.0, with a specific focus on the relation between technology and human factors. Indeed, in the taxonomy development, along with the main category related to the logistics activities (Internal Logistics Activities), two new categories have been conceptualized to take into consideration the relevant aspects of Logistics 4.0: (i) the improvement of information flows thanks to the availability of a considerable amount of data (Flow types), and (ii) the necessity of combining the new technological application with the human work (Humantechnology relation). 
After the choice of the categories and dimensions as described in Section 3.1, during the taxonomy development, it was possible to highlight that some internal logistics areas shared exactly the same objects, equally classified according to the other dimensions.

For this reason, some areas have been merged in a unique dimension: Storage and Stowage have been considered in the same dimension, while Packing, Labelling, Kitting and Consolidation have been merged in the Packing and Delivering dimension.

\subsection{Taxonomy}

At this point, it was possible to proceed with creating the actual taxonomy of the technologies adopted in the various activities of internal logistics, based on the categories and dimensions illustrated in the previous sections. The taxonomy results are reported in Table 6.

Table 6. Taxonomy.

\begin{tabular}{|c|c|c|c|}
\hline \multirow{2}{*}{$\begin{array}{l}\text { Internal Logistics } \\
\text { Activities }\end{array}$} & \multirow{2}{*}{$\begin{array}{c}\text { Human-Technology } \\
\text { Relation }\end{array}$} & \multicolumn{2}{|c|}{ Flow Types } \\
\hline & & Material Flows & Information Flows \\
\hline \multirow{2}{*}{ Picking } & Support & $\begin{array}{c}\text { Exoskeletons (lifting) } \\
\text { Autmated Guided } \\
\text { Vehicles-AGV (picking) } \\
\text { Drones (picking) } \\
\text { Collaborative Robots (picking) }\end{array}$ & $\begin{array}{c}\text { Handheld Computers } \\
\text { (picking information) } \\
\text { Wearable Scanners } \\
\text { (barcodes, RFID tags) } \\
\text { Voice-Direct Headsets (voice picking) } \\
\text { Smart Glasses (pick-put to light) } \\
\text { Activity Trackers (steps, heart-rate) }\end{array}$ \\
\hline & Automation & $\begin{array}{c}\text { Smart Fast Rotation Storage } \\
\text { Systems } \\
\text { Smart Trasloelevators } \\
\text { Smart Mini-Loaders }\end{array}$ & $\begin{array}{l}\text { Order Management Systems (OMS) } \\
\text { Inventory Management Systems } \\
\text { (IMS) } \\
\text { Picking Route Management Systems } \\
\text { (PRMS) } \\
\text { Scheduling Management Systems } \\
\text { (SMS) }\end{array}$ \\
\hline \multirow[t]{2}{*}{ Packing and delivering } & Support & $\begin{array}{c}\text { Collaborative Robots } \\
\text { (inspection, kitting, and } \\
\text { packing) }\end{array}$ & Labelling Systems \\
\hline & Automation & $\begin{array}{l}\text { Industrial Robots (inspection, } \\
\text { kitting, and packing) }\end{array}$ & Order Management Systems (OMS) \\
\hline \multirow[t]{2}{*}{ Storage and Stowage } & Support & $\begin{array}{l}\text { Exoskeletons (moving) } \\
\text { AGVs (moving) } \\
\text { Drones (moving) } \\
\text { Collaborative Robots } \\
\text { (load-n'-unload) }\end{array}$ & Smart Sensors (beacon tags) \\
\hline & Automation & $\begin{array}{c}\text { Smart Fast Rotation Storage } \\
\text { Systems } \\
\text { Smart Trasloelevators } \\
\text { Smart Mini-Loaders }\end{array}$ & $\begin{array}{l}\text { Inventory Management Systems } \\
\text { (IMS) } \\
\text { Warehouse Management Systems } \\
\text { (WMS) }\end{array}$ \\
\hline \multirow[t]{2}{*}{$\begin{array}{l}\text { Material } \\
\text { Handling }\end{array}$} & Support & $\begin{array}{l}\text { Exoskeletons (moving) } \\
\text { AGVs (moving) } \\
\text { Drones (moving) } \\
\text { Collaborative Robots } \\
\text { (load-n'-unload) }\end{array}$ & $\begin{array}{l}\text { Smart Sensors (beacon tags) } \\
\text { Wearable Devices }\end{array}$ \\
\hline & Automation & $\begin{array}{l}\text { Auto-ID Technologies (RFID) } \\
\text { Smart Lifts and Forklifts } \\
\text { Wearable Devices }\end{array}$ & $\begin{array}{l}\text { Warehouse Management Systems } \\
\text { (WMS) } \\
\text { Inventory Resources Planning (IRP) }\end{array}$ \\
\hline
\end{tabular}




\subsection{Discussion}

From an initial analysis of the taxonomy, two main results became immediately apparent. In some activities, there is a more significant number of technologies adopted, and, in general, they are applied more for the management of material flows than for information flows. The first result is not surprising, as picking and material handling activities are, in fact, primarily repetitive and dangerous activities (especially material handling, when materials are handled at high altitudes) for which human intervention is limited [34]. This motivation explains the presence of a large number of automationrelated technologies in both areas. However, in some subtasks related to picking (e.g., item identification and recording) and material handling (e.g., rapid and precision movements, loading-unloading), human intervention is still needed for its peculiar characteristics (e.g., articulated movements, cognitive skills). Indeed, the technologies are not yet mature enough to carry out specific operations with precision, speed and (above all) with a minimum space requirement (compared, for example, to the requirement for a collaborative or autonomous robot to carry out the same activities).

As regards the preponderance of applications for the management of material flows compared to the management of information flows, we can say that the cause is mainly to be found in the level of maturity of the technologies themselves. It is thought that in the future, with the development of enabling accessory and infrastructure technologies (such as $5 \mathrm{G}$ and blockchain) there will be an increasing number of applications technologies for the support of information flows in storage. It is also necessary to highlight that not all the technologies in Table 4 have reached the same level of maturity. For some technologies, such as drones and collaborative robots, there are ways of use still not fully explored. Another element that puts a brake on developing other technologies for flow management is still a low level of integration between different technologies. Adopting standards is still a barrier to integration between different management software with different functionalities, between management systems and hardware technologies, and between hardware technologies themselves [47]. Even if an increasing number of important steps are being taken to evolve the traditional factory into a smart factory, there are still some problems to solve, especially, as mentioned above, at the level of integration between different technologies. However, the investments in research, the continuous monitoring of pilot applications, the existence of pioneering companies that have already begun to invest in cutting-edge technologies, and the great importance that is increasingly given to the construction of digital supply chains (to create increasingly flexible and efficient supply chains) suggest that soon the technologies adopted for flow management will be more numerous [35].

Finally, it should be noted that the taxonomy does not show differences between support and automation technologies. There is no preponderance of one dimension over the other. This result happens because, as already found in literature, the twodimensional typologies are not alternatives to each other but proceed in parallel. The choice of automating or supporting the execution of a particular activity does not depend so much on the degree of maturity reached by the technology that one wishes to apply but on the intrinsic characteristics of that activity and on the impact that these characteristics have on the operator (i.e., human factors) who carries out that activity.

\section{Conclusions}

The present research work aims at realizing a taxonomy of the leading technologies implemented in the activities related to internal logistics. The taxonomy was based on the identification of three main categories (i.e., internal logistics activities, flow types, human-technologies relation) and the classification of the taxonomy objects (i.e., the different specific technological applications) according to them. The taxonomy has shown how the penetration of technologies is more evident in activities linked to picking and material handling. These activities are notoriously more repetitive, and can involve a higher risk factor for the safety of operators but, at the same time, they include activities 
that cannot be automated entirely due both to some peculiar characteristics that require human intervention and to the low level of technological maturity reached so far. It has also been observed that there is a large number of technological applications in material flow management compared to information flow management. This result is due to the technological evolution still in progress. At the time this research was carried out, we began to see the first applications of enabling infrastructure technologies for the management and exchange of information flows such as 5G or blockchains. Finally, no substantial differences emerged between the implementation of automation technologies versus support technologies, the number of applications being equivalent because the two dimensions are not alternatives but proceed in parallel.

The work has limitations, mainly because the categories of the taxonomy have been exclusively identified inductively from the scientific literature. Another limitation concerns the identification of the taxonomy objects that have been identified only by reviewing works and applications published by the academic community. Indeed, it would be necessary to undertake a review of the existing additional technologies applied in the industry and by suppliers so that the list of objects of the taxonomy could be updated regularly and frequently.

It is assumed that these limitations can be overcome in later phases of the research. First, performing a joint inductive-deductive approach could be crucial to refining the taxonomy and validating the classification performed with cases. In doing this, industrial stakeholders could be involved, through surveys, case studies and interviews, in order to enlarge or better define the categories and dimensions of classification, along with the taxonomy objects. Moreover, the taxonomy could be used as a reference framework to support systematic literature reviews concerning the topics of the relation between Industry 4.0 technologies, logistics, and the operator's role. Furthermore, testing the taxonomy based on industrial application could be useful to identify unexpected utilization of the technologies can suggest further modifications and improvements in the currently proposed taxonomy. The work presented in this paper is, in fact, part of a larger research project aimed at analyzing the relationship between technology evolution and the impact it has on operators and managers working in the field of logistics in order to have both a greater understanding of logistics activities and to support managers and companies in a correct choice of the types of technology to adopt according to different needs.

Author Contributions: Conceptualization, A.L.; methodology, C.C.; validation, F.P.; writingoriginal draft preparation, A.L. and C.C.; writing-review and editing, F.P. and R.P.; supervision, R.P. All authors have read and agreed to the published version of the manuscript.

Funding: This research received no external funding.

Institutional Review Board Statement: Not applicable.

Informed Consent Statement: Not applicable.

Conflicts of Interest: The authors declare no conflict of interest.

\section{References}

1. Xu, L.D.; Xu, E.L.; Li, L. Industry 4.0: State of the Art and Future Trends. Int. J. Prod. Res. 2018, 56, 2941-2962. [CrossRef]

2. Kuhn, M.; Schaefer, F.; Otten, H. Process Complexity as a Future Challenge-A Quality Management Perspective. TQM J. 2018, 30, 701-716. [CrossRef]

3. Cimini, C.; Lagorio, A.; Romero, D.; Cavalieri, S.; Stahre, J. Smart Logistics and The Logistics Operator 4.0. IFAC-Pap. 2020, 53, 10615-10620. [CrossRef]

4. Cimini, C.; Boffelli, A.; Lagorio, A.; Kalchschmidt, M.; Pinto, R. How Do Industry 4.0 Technologies Influence Organisational Change? An Empirical Analysis of Italian SMEs. J. Manuf. Technol. Manag. 2020, 32, 695-721. [CrossRef]

5. Neumann, W.P.; Winkelhaus, S.; Grosse, E.H.; Glock, C.H. Industry 4.0 and the Human Factor-A Systems Framework and Analysis Methodology for Successful Development. Int. J. Prod. Econ. 2021, 233, 107992. [CrossRef]

6. Tokar, T.; Williams, B.D.; Fugate, B.S. I Heart Logistics-Just Don't Ask Me to Pay For It: Online Shopper Behavior in Response to a Delivery Carrier Upgrade and Subsequent Shipping Charge Increase. J. Bus. Logist. 2020, 41, 182-205. [CrossRef] 
7. Mehrotra, P.; Malani, P.; Yadav, P. Personal Protective Equipment Shortages During COVID-19—Supply Chain-Related Causes and Mitigation Strategies. JAMA Health Forum 2020, 1, e200553. [CrossRef]

8. Winkelhaus, S.; Grosse, E.H. Logistics 4.0: A Systematic Review towards a New Logistics System. Int. J. Prod. Res. 2019, 58, 18-43. [CrossRef]

9. Facchini, F.; Oleśków-Szłapka, J.; Ranieri, L.; Urbinati, A. A Maturity Model for Logistics 4.0: An Empirical Analysis and a Roadmap for Future Research. Sustainability 2019, 12, 86. [CrossRef]

10. Nickerson, R.C.; Varshney, U.; Muntermann, J. A Method for Taxonomy Development and Its Application in Information Systems. Eur. J. Inf. Syst. 2013, 22, 336-359. [CrossRef]

11. López, T.S.; Ranasinghe, D.C.; Patkai, B.; McFarlane, D. Taxonomy, Technology and Applications of Smart Objects. Inf. Syst. Front. 2011, 13, 281-300. [CrossRef]

12. Oberländer, A.M.; Lösser, B.; Rau, D. Taxonomy Research in Information Systems: A Systematic Assessment. In Proceedings of the Proceedings of the 27th European Conference on Information Systems (ECIS), Stockholm \& Uppsala, Sweden, 8-14 June 2019.

13. Fiedler, K.D.; Grover, V.; Teng, J.T.C. An Empirically Derived Taxonomy of Information Technology Structure and Its Relationship to Organizational Structure. J. Manag. Inf. Syst. 1996, 13, 9-34. [CrossRef]

14. Land, L.; Smith, S.; Pang, V. Building a Taxonomy for Cybercrimes. In Proceedings of the PACIS 2013 Proceedings; $2013 ;$ p. 109.

15. Fellmann, M.; Koschmider, A.; Laue, R.; Schoknecht, A.; Vetter, A. Business Process Model Patterns: State-of-the-Art, Research Classification and Taxonomy. Bus. Process Manag. J. 2018, 25, 972-994. [CrossRef]

16. de Lima, O.P.; Santiago, S.B.; Taboada, C.M.R.; Rodríguez, J.L.M.; Rodríguez, M.B.R.; Maduro, M.R.; Araújo, P.C.D., Jr.; Zogahib, A.L.N.; Lima, J.C. Conceptualization, Definition and Assessment of Internal Logistics through Different Approaches Using Artificial Intelligence; IntechOpen: London, UK, 2020; ISBN 978-1-83881-202-7.

17. Morash, E.A.; Dröge, C.; Vickery, S. Boundary Spanning Interfaces between Logistics, Production, Marketing and New Product Development. Int. J. Phys. Distrib. Logist. Manag. 1996, 26, 43-62. [CrossRef]

18. Delgado, C.; Castelo, B.M. Supply Chain Management. In Encyclopedia of Corporate Social Responsibility; Idowu, S.O., Capaldi, N., Zu, L., Gupta, A.D., Eds.; Springer: Berlin/Heidelberg, Germany, 2013; ISBN 978-3-642-28036-8.

19. Kulak, O. A Decision Support System for Fuzzy Multi-Attribute Selection of Material Handling Equipments. Expert Syst. Appl. 2005, 29, 310-319. [CrossRef]

20. Buxton, G. Warehouse Management and Materials Handling. In Effective Marketing Logistics: The Analysis, Planning and Control of Distribution Operations; Buxton, G., Ed.; Palgrave Macmillan: London, UK, 1975; pp. 125-144. ISBN 978-1-349-02101-7.

21. Goetschalckx, M.; Ashayeri, J. Classification and Design of Order picking. Logist. World 1989, 2, 99-106. [CrossRef]

22. Yuan, R.; Cezik, T.; Graves, S.C. Stowage Decisions in Multi-Zone Storage Systems. Int. J. Prod. Res. 2018, 56, 333-343. [CrossRef]

23. Saghir, M. Packaging Logistics Evaluation in the Swedish Retail Supply Chain; Packaging Logistics, Lund University: Lund, Sweden, 2002; ISBN 978-91-628-5272-6.

24. Soroka, W. Fundamentals of Packaging Technology, 3rd ed.; Inst of Packaging Professionals: Naperville, IL, USA, 2002; ISBN 978-1-930268-25-8.

25. Brynzér, H.; Johansson, M.I. Design and Performance of Kitting and Order Picking Systems. Int. J. Prod. Econ. 1995, 41, 115-125. [CrossRef]

26. Tyan, J.C.; Wang, F.-K.; Du, T.C. An Evaluation of Freight Consolidation Policies in Global Third Party Logistics. Omega 2003, 31, 55-62. [CrossRef]

27. Christopher, M. Logistics \& Supply Chain Management; Pearson: London, UK, 2016; ISBN 978-1-292-08382-7.

28. Alicke, K.; Rachor, J.; Seyfert, A. Supply Chain 4.0—the next-Generation Digital Supply Chain. McKinsey. 2016. Available online: https:/ / www.mckinsey.com/business-functions/operations/our-insights/supply-chain-40--the-next-generation-digitalsupply-chain (accessed on 15 September 2021).

29. Scuotto, V.; Caputo, F.; Villasalero, M.; Giudice, M.D. A Multiple Buyer-Supplier Relationship in the Context of SMEs' Digital Supply Chain Management. Prod. Plan. Control 2017, 28, 1378-1388. [CrossRef]

30. Hanifan, G.; Sharma, A.; Newberry, C. The Digital Supply Network. New Paradigm Supply Chain Manag. 2014, 8.

31. Chopra, S.; Meindl, P. Supply Chain Management: Strategy, Planning, and Operation, 5th ed.; Pearson: Boston, MA, USA, 2013; ISBN 978-0-13-274395-2.

32. Zoubek, M.; Simon, M. Evaluation of the Level and Readiness of Internal Logistics for Industry 4.0 in Industrial Companies. Appl. Sci. 2021, 11, 6130. [CrossRef]

33. Cimini, C.; Lagorio, A.; Pirola, F.; Pinto, R. Exploring Human Factors in Logistics 4.0: Empirical Evidence from a Case Study. IFAC-Pap. 2019, 52, 2183-2188. [CrossRef]

34. Cimini, C.; Lagorio, A.; Pirola, F.; Pinto, R. How Human Factors Affect Operators' Task Evolution in Logistics 4.0. Hum. Factors Ergon. Manuf. Serv. Ind. 2021, 31, 98-117. [CrossRef]

35. Lagorio, A.; Zenezini, G.; Mangano, G.; Pinto, R. A Systematic Literature Review of Innovative Technologies Adopted in Logistics Management. Int. J. Logist. Res. Appl. 2020. [CrossRef]

36. Hassan, M.; Ali, M.; Aktas, E.; Alkayid, K. Factors Affecting Selection Decision of Auto-Identification Technology in Warehouse Management: An International Delphi Study. Prod. Plan. Control 2015, 26, 1025-1049. [CrossRef]

37. Romero, A.; Lefebvre, E. Combining Barcodes and RFID in a Hybrid Solution to Improve Hospital Pharmacy Logistics Processes. Int. J. Inf. Technol. Manag. 2015, 14, 97-123. [CrossRef] 
38. Hazen, B.T.; Byrd, T.A. Toward Creating Competitive Advantage with Logistics Information Technology. Int. J. Phys. Distrib. Logist. Manag. 2012, 42, 8-35. [CrossRef]

39. Gunasekaran, A.; Subramanian, N.; Papadopoulos, T. Information Technology for Competitive Advantage within Logistics and Supply Chains: A Review. Transp. Res. Part E Logist. Transp. Rev. 2017, 99, 14-33. [CrossRef]

40. Subramanian, N.; Abdulrahman, M.D.; Zhou, X. Integration of Logistics and Cloud Computing Service Providers: Cost and Green Benefits in the Chinese Context. Transp. Res. Part E Logist. Transp. Rev. 2014, 70, 86-98. [CrossRef]

41. Baghdadi, A.; Megahed, F.M.; Esfahani, E.T.; Cavuoto, L.A. A Machine Learning Approach to Detect Changes in Gait Parameters Following a Fatiguing Occupational Task. Ergonomics 2018, 61, 1116-1129. [CrossRef]

42. Cole, R.; Lindsay, C.F.; Barker, F. Reverse Exchange of Healthcare Devices: The Case of Hearing Aid Equipment in the UK. Prod. Plan. Control 2018, 29, 1045-1057. [CrossRef]

43. Sedighi Maman, Z.; Alamdar Yazdi, M.A.; Cavuoto, L.A.; Megahed, F.M. A Data-Driven Approach to Modeling Physical Fatigue in the Workplace Using Wearable Sensors. Appl. Ergon. 2017, 65, 515-529. [CrossRef] [PubMed]

44. Roy, D.; Krishnamurthy, A.; Heragu, S.S.; Malmborg, C. A Multi-Tier Linking Approach to Analyze Performance of Autonomous Vehicle-Based Storage and Retrieval Systems. Comput. Oper. Res. 2017, 83, 173-188. [CrossRef]

45. Appelbaum, D.; Nehmer, R.A. Using Drones in Internal and External Audits: An Exploratory Framework. J. Emerg. Technol. Account. 2017, 14, 99-113. [CrossRef]

46. DHL. Trend Research Self-Driving Vehicles in Logistics 2014; DHL: San Francisco, CA, USA.

47. Jagtap, S.; Bader, F.; Garcia-Garcia, G.; Trollman, H.; Fadiji, T.; Salonitis, K. Food Logistics 4.0: Opportunities and Challenges. Logistics 2020, 5, 2. [CrossRef] 